\title{
EL PROBLEMA DE LA DIFICULTAD CONTRAMAYORITARIA DE LA JUSTICIA CONSTITUCIONAL DESDE LA PERSPECTIVA DE LA LEGITIMIDAD DE REFLEXIVIDAD en PIerRe RosanvalloN
}

\section{Fernando D. Álvarez Álvarez}

\author{
Universidad Austral. Universidad Católica Argentina \\ fernando.alvarez3@gmail.com
}

Recibido: 26/08/2021

Aceptado: $12 / 10 / 2021$

\section{Resumen}

El presente estudio aborda el problema de la dificultad contramayoritaria que se les suele imputar a los tribunales que ejercen control de constitucionalidad. Para superar dicha dificultad, se asume la perspectiva de la legitimidad de reflexividad conceptualizada por Pierre Rosanvallon. Con apoyo en las teorizaciones de este autor y enriqueciendo el análisis y la argumentación con diferentes conceptos provenientes del derecho constitucional y de la teoría de la democracia, se propone una hipótesis innovadora: el rol democrático de los tribunales constitucionales y de la reflexividad jurídica en general no remite a fundamentos liberales, sino propiamente democráticos dada la imposibilidad de identificación entre la voluntad del pueblo soberano y la voluntad de los representantes. De este modo, el trabajo pretende dar cuenta, de manera clara y fundada, cómo los tribunales constitucionales pueden cristalizar, en la perspectiva de una democracia compleja, nuevas formas de representación. Si bien la pluralidad necesita ser condensada, simplificada, por los procesos electorales para erigir mayorías gobernantes, como contraparte es imprescindible que existan instancias reflexivas que recompongan la diversidad a través del debate público, poniendo freno a las decisiones mayoritarias, especialmente cuando estas invaden la esfera de los derechos humanos fundamentales. Adicionalmente, puede resultar de especial interés el tratamiento de la cuestión de la temporalidad plural de la democracia, aspecto al que no se le suele prestar atención desde la teoría política y jurídica.

Palabras clave: control judicial de constitucionalidad, dificultad contramayoritaria, legitimidad democrática, legitimidad de reflexividad, democracia constitucional, tribunales constitucionales, democracia. 


\title{
The Problem of the Counter - Majoritarian Difficulty of Constitutional Justice from the Perspective of the Legitimacy of Reflexivity in Pierre Rosanvallon
}

\begin{abstract}
The present study deals with the problem of counter-majoritarian difficulty that usually is attributed to courts of law that apply constitutional review. To overpass such difficulty, it assumes Pierre Rosanvallon's legitimacy of reflexivity perspective. By relying on this author's theorizations and enriching the analysis and argumentation with different Constitutional Law and Democratic Theory concepts, the article proposes an innovative hypothesis: the democratic role of constitutional courts and of legal reflexivity in general does not refer to liberal grounds, but properly democratic ones, because of the impossibility of identification between the sovereign people and the representatives' will. In this way, the article pretends to give an account of how constitutional courts can crystallize, in the perspective of a complex democracy, new forms of representation. Even when the plurality needs to be thicken, simplified, by electoral processes to raise ruling majorities, as a counterpart it is indispensable the existence of reflexive agencies to recompose the diversity through public debate, to put a stop to majoritarian decisions, especially when they invade the sphere of fundamental human rights. Additionally, the matter of democracy's plural temporality can be of especial interest, as an aspect not considered in political and legal theory.
\end{abstract}

Key words: judicial review, counter majoritarian difficulty, democratic legitimacy, legitimacy of reflexivity, constitutional democracy, constitutional courts, democracy.

\section{Introducción}

\subsection{Los problemas en juego}

... when the Supreme Court declares unconstitutional a legislative act or the action of an elected executive, it thwarts the will of representatives of the actual people of the here and now; it exercises control, not in behalf of the prevailing majority, but against it. That, without mystic overtones, is what actually happens. It is an altogether different kettle of fish, and it is the reason the charge can be made that judicial review is undemocratic.

(Bickel, 1986, pp. 16-17) ${ }^{1}$

Tanto en el ámbito político como en cualquier otro de la vida social (en la

1 “... cuando la Suprema Corte declara inconstitucional una ley o el acto de un ejecutivo electo popularmente frustra la voluntad de los representantes del pueblo aquí y ahora; ejerce el control no en favor de la mayoría, sino en su contra. Esto, sin misticismos, es lo que sucede realmente. Es una olla de pescado totalmente diferente y es la razón por la que se puede formular la acusación de que la revisión judicial es antidemocrática" (traducción del autor). 
empresa, en la escuela o en la familia), muchas veces, cuando debemos tomar una decisión como forma de dotar de legitimidad a aquello que se decidirá, convenimos en hacerlo democráticamente. La democracia se ha convertido en un procedimiento de toma de decisiones que se reputan legítimas y que consiste básicamente en decidir por mayoría. Lo democrático expresa, pues, las preferencias mayoritarias. Sin embargo, y como lo examinaremos más adelante, esa mayoría encierra una pretensión de generalidad, pues tiende a identificarse con la voluntad de todos.

Este fenómeno es observable en la propia evolución histórica de la democracia. En efecto, los regímenes democráticos instituidos a finales del siglo XVIII y en la centuria siguiente se fundan en, al menos, dos ficciones (Rosanvallon, 2009, p. 22). La primera consiste en afirmar que la parte vale por el todo, esto es, la mayoría (que es una fracción, aunque sea predominante) es tomada como si valiera por la totalidad. En consecuencia, la improbable unanimidad (que expresaría estrictamente la generalidad) acoge como sucedáneo factible la regla mayoritaria. Así, la voluntad de la mayoría equivale a la voluntad de todos. Por su parte, la segunda ficción consiste en postular que la legitimidad lograda por aplicación de la regla mayoritaria en el momento electoral se prolonga por toda la duración del mandato. Rosanvallon (2009, p. 23) considera a estas como las dos ficciones fundadoras sobre las que se asentó la legitimidad del régimen democrático. La democracia, en suma, obtiene su legitimidad de su identificación con la regla mayoritaria, y esta legitimidad de origen se solapa, confundiéndose, con la de ejercicio, puesto que la unción popular-electoral proyecta automáticamente su efecto legitimador a todo el mandato. Por supuesto que este mismo aparato ficcional se proyecta sobre los productos de los representantes: por ejemplo, la ley, necesariamente votada por mayoría, es la expresión máxima de la voluntad popular.

Sin embargo, nuestros sistemas jurídico-políticos han incorporado otro tipo de institución, cuyos integrantes no son elegidos por el pueblo electoralmente: los tribunales en general y los tribunales constitucionales en particular. Hasta allí la cosa no es tan grave, porque, bien pensado, la gran burocracia estatal, particularmente concentrada en la Administración pública, tampoco es el resultado de elecciones populares y tiene un poder nada desdeñable en las sociedades contemporáneas (incluso, tal vez tengan demasiado poder). Pero hay una diferencia amenazadora: mientras que la Administración se encuentra totalmente sometida a la ley (por lo menos en el mundo del "deber ser"), los 
tribunales constitucionales, ${ }^{2}$ presentada la oportunidad, tienen la facultad de fulminar (con efectos singulares o generales) la decisión legislativa -paradigmático producto de la voluntad popular-, declarándola inconstitucional. ${ }^{3}$ Entonces, surge como un rayo la pregunta insoslayable: ¿cómo puede considerarse legítimo democráticamente que un puñado de jueces no elegidos electoralmente por el pueblo puedan dejar sin efecto la ley (desde no aplicarla al caso concreto a ser derogada, según el sistema de control de constitucionalidad del que se trate), que es la expresión máxima de la soberanía? En esto consiste la denominada dificultad contramayoritaria de la justicia constitucional, que parece ubicar a los tribunales que la integran en la vereda de enfrente de la democracia. Es decir, si todo lo que hemos dicho hasta aquí sobre la democracia la define con certeza y plenitud, la conclusión inevitable es que la jurisdicción constitucional es contramayoritaria y, en ese sentido, antidemocrática.

Precisamente en este trabajo pretendemos echar un poco de luz sobre este problema cada vez más acuciante, teniendo muy particularmente en cuenta para ello los estudios que ha llevado adelante Pierre Rosanvallon, quien ha desarrollado en los últimos años una serie de teorizaciones que conforman una novedosa perspectiva, jalonada de valiosas herramientas, que permiten apreciar con una mirada renovada la democracia y sus mutaciones. Por supuesto que el intentar resolver con mayor felicidad para la justicia constitucional la dificultad contramayoritaria nos conducirá por una serie de cuestiones aún más de fondo, que nos llevará a preguntarnos qué es (o debería ser) la democracia hoy. La tarea es ardua porque implica un viaje desde las ficciones que señala Rosanvallon -que implican ya insostenibles falsificaciones sobre la realidad-para intentar aprehender conceptos y realidades más complejos y, nos animamos a decir, más verdaderos.

2 A los fines de este trabajo, y con el objeto de comprender el más amplio universo de sistemas de control de constitucionalidad judicial posible, vamos a entender por tribunal constitucional a todo aquel habilitado para ejercer control de constitucionalidad, tanto se trate de sistemas de control concentrado como difuso, preventivo o reparador, por vía directa o indirecta, con legitimaciones activas tanto restringidas como amplias y con efecto inter-partes o erga omnes, cuyos integrantes no sean elegidos electoralmente. En síntesis, los elementos decisivos de este concepto de tribunal constitucional son: a) su naturaleza judicial; b) que sus miembros no sean elegidos popularmente; y c) que tengan reconocida -explícita o implícitamente- la facultad de ejercer control de constitucionalidad.

3 La intensidad y extensión de este poder es variable según cuál sea el sistema de control de constitucionalidad imperante en cada Estado. Por supuesto que los tribunales que ejercen control de constitucionalidad pueden declarar la inconstitucionalidad de todos los actos y normas dictados por los poderes estatales, pero la objeción contramayoritaria se hace más patente y acuciante cuando se trata de una ley formal, es decir, dictada por el Parlamento, Congreso o Legislatura, por tratarse de órganos en los que, convencionalmente, se concentra -entre los poderes constituidos- la soberanía popular. 


\subsection{Las nuevas legitimidades de Pierre Rosanvallon}

A lo largo del siglo XX, la concepción procedimental de la democracia que implicaba la automaticidad de la legitimidad como consecuencia de un resultado electoral fue perdiendo paulatinamente credibilidad. La crisis de los partidos políticos, la pérdida de confianza en los dirigentes y en las instituciones políticas, el clientelismo y otros factores corroyeron la representatividad de los electos y la propia noción de que la mayoría electoral era la expresión del pueblo o de la generalidad. ${ }^{4}$ En consecuencia, la legitimidad entendida como una cualidad jurídica, estrictamente procedimental, que es producida de modo perfecto y absoluto por la elección, se desgasta y pierde eficacia. El desencanto y la desconfianza ${ }^{5}$ que resultará de este proceso darán lugar a la aparición de otras formas de legitimidad, que comenzarán a convivir con la de cuño electoral.

Rosanvallon detecta -a partir de la década de 1980- el surgimiento de una nueva era de la legitimidad, que ha dotado a lo que consideramos como democráticamente legítimo de una nueva densidad y hondura. Así, sostiene este autor, son reconocibles tres nuevas formas de legitimidad, que se compadecen con otros tantos nuevos modos de aprehender el imperativo democrático de expresión de la generalidad social:

a. La legitimidad de imparcialidad: consiste básicamente en distanciarse de las posiciones partidistas y de los intereses particulares, de modo que "es legítimo aquello que se muestra como imparcial, desinteresado, y que cumple con la exigencia de unanimidad" (Annunziata, 2012, p. 48). Combina la independencia del poder electoral (variable estructural) con el mantenimiento de la distancia o el equilibrio (variable de comportamiento). Este tipo de legitimi-

4 En rigor, Rosanvallon (2009) sostiene que la democracia encontró sustento en dos formas de legitimidad. Por un lado, encontramos la legitimidad electoral, degradada por las sucesivas crisis de representatividad, y, por otro lado, se encuentra la legitimidad como identificación con la generalidad social, la cual fue forjada a través del poder administrativo, de manera que "la "maquinaria burocrática' constituyera en sí misma una fuerza identificada con la realización del interés general” (p. 24). En esta última especie, los funcionarios eran llamados a volverse "interesados en el desinterés" y a buscar "el acceso a la generalidad mediante las virtudes de una gestión científica". Mientras que a la legitimidad electoral se accedía mediante el voto, a la legitimidad producto de la identificación con la generalidad mediante el poder administrador se accedía por el concurso público. Esta segunda forma de la legitimidad fue debilitada por una retórica neoliberal cuestionadora de la respetabilidad del Estado, que, además, invitó a erigir al mercado como un nuevo mecanismo instituyente del bienestar colectivo (p. 26). En consecuencia, el sistema de la mentada doble legitimidad resultó sustancialmente debilitado, permitiendo el advenimiento de otras formas de legitimidad a partir de 1980.

5 Rosanvallon describe de modo muy interesante este proceso de conformación de una sociedad de la desconfianza en La contrademocracia. La política en la era de la desconfianza (2007), especialmente en pp. 21-42. 
dad define un poder entendido como lugar vacío, de manera que la calidad de generalidad de una institución que goza de legitimidad de imparcialidad está por el hecho de que nadie puede apropiársela; en este sentido, se trata de una generalidad negativa. Es la legitimidad que se les reconoce a las autoridades de control o regulación (Rosanvallon, 2009, p. 28).

b. La legitimidad de reflexividad: aquí se trata de multiplicar los enfoques parciales para lograr una comprensión más plural de las cosas y, por ende, más completa. Es una "generalidad por multiplicación" (Rosanvallon, 2009, p. 28). De esta manera, la tarea a llevar a cabo por la reflexividad consiste en corregir, mediante mecanismos compensadores, la incompletitud de la democracia electoral. Es decir que la legitimidad de reflexividad trata especialmente de corregir los incumplimientos resultantes de la asimilación de la mayoría electoral a la voluntad del cuerpo social tomado en su globalidad. Un tribunal constitucional gozaría de este tipo de legitimidad al hacer pasar por el tamiz de la Constitución las decisiones adoptadas por el partido mayoritario (p. 28). La pluralidad necesita ser condensada, simplificada, por los procesos electorales para erigir mayorías gobernantes. Sin embargo, como contraparte, existen instancias reflexivas que recomponen la diversidad a través del debate público, poniéndoles freno a las decisiones mayoritarias, especialmente cuando estas invaden el "coto vedado" de los derechos.

c. La legitimidad de proximidad: "La proximidad supone [...] una inmersión radical en el mundo de la particularidad, una preocupación por los individuos concretos, una extensión en el campo de atención o [...] un descenso a la generalidad" (Annunziata, 2012, p. 48). En efecto, de lo que se trata aquí es de "tomar en consideración la multiplicidad de situaciones, mediante el reconocimiento de todas las singularidades sociales". Si se la aprecia como cualidad de un comportamiento, es el resultado de "la acción de un poder que no olvida a nadie, que se interesa en los problemas de todos" (Rosanvallon, 2009, p. 28), implica, pues, una cercanía y una empatía que supere la distancia impuesta por la representación tradicional en el vínculo entre gobernantes y gobernados.

En nuestro análisis nos interesa considerar la denominada dificultad contramayoritaria de los jueces desde la perspectiva que ofrece la legitimidad de reflexividad. A continuación, indagaremos un poco más sobre este tipo de legitimidad en el pensamiento de Pierre Rosanvallon. 


\section{La democracia reflexiva}

Estado se llama al más frio de todos los monstruos fríos. Es frio incluso cuando miente; y ésta es la mentira que se desliza de su boca: "Yo, el Estado, soy el pueblo"

(Nietzsche, como se citó en Vita, 2009, p. 214)

Rosanvallon (2009) explica que la concepción electoral representativa de la democracia, puramente procedimental, se estructura a partir de tres presupuestos: a) "la identificación de la opción electoral con la expresión de la voluntad general"; b) "la asimilación de los electores con el pueblo"; c) "la perdurable inscripción de la actividad política y parlamentaria en la continuidad del momento electoral" (p. 183). Esta concepción de la democracia es, para este autor, una versión moderada de lo que denomina la "democracia inmediata".

Vale la pena detenerse en este concepto y en sus implicancias para comprender mejor la tarea correctiva y compensadora que la reflexividad y sus instituciones deberán llevar a cabo sobre esta concepción de la democracia.

La democracia inmediata remite implícitamente a la idea de gobierno popular que se instala con la Revolución Francesa, en la cual el poder constituyente es la expresión más fiel del ideal democrático que, cuando es originario, debe crear un nuevo régimen como si no hubiese habido historia, es decir, es fundacional ex nihilo. El pueblo debe reunirse y, siguiendo su sentido común, tomar todas las decisiones necesarias, catalizando una "'electricidad moral', vector natural de una manifestación unánime”. Así, el poder constituyente expresa una soberanía originaria, extraordinaria, incondicionada, suprema y directa. Tiene la necesidad de producir una ruptura absoluta con el pasado (en el caso, con la herencia monárquica), de manera que solo el presente pueda ser revolucionario, transformándose la voluntad popular en "la versión secularizada del poder divino de crear un orden sin estar sometido a él" (Rosanvallon, 2009, p. 185). En esta inteligencia, la democracia solamente es concebible al cabo de una revolución, en tanto conforma una fuerza insurreccional imparable que opera una desinstitucionalización radical de la política. ${ }^{6}$ Este orden de ideas, que encuentra la explicación de su origen en razones predominantemente históricas, se proyectó hacia adelante traduciéndose en una democracia monista y

6 Esta identificación entre soberanía popular y una radical autoinstitucionalización de lo social reaparecerá con fuerza en el decisionismo de Schmitt y en la perspectiva comunista de un "Estado para todo el pueblo" (Rosanvallon, 2009, pp. 186 y 188). 
unidimensional, que perdurará -instauración de la representación mediantebajo la forma de un hiperelectoralismo (Rosanvallon, 2009, p. 189).

Rosanvallon (2009) va a contrastar la democracia inmediata con lo que él denomina democracia compleja, "basada en la diversificación cruzada de las temporalidades y de los modos de expresión de la vida política” (p. 190). Para ello, reivindicará parte del pensamiento de Condorcet. Mientras que muchos de los contemporáneos del girondino pensaban que el régimen representativo era un sucedáneo práctico de la improbable democracia directa, él revisa el problema y se plantea el camino para conformar una democracia representativa. Para ello es necesario pluralizar los modos en los que se ejerce la soberanía popular, que no puede agotarse en el sufragio ni en las decisiones de los representantes electos en su consecuencia. ${ }^{7}$ Esta visión permite reinterpretar la división de poderes, que deja de ser un reparto más o menos equilibrado de prerrogativas para ser una condición de la profundización de la democracia, convirtiéndose en un canal de la participación de un sujeto necesariamente plural como es el pueblo. Es decir, la multiplicación de las expresiones parciales es la mejor vía para acceder a una aproximación de conjunto. En esta inteligencia, el poder social se torna más efectivo si se pluralizan los medios de involucramiento de las partes del todo social, lo cual requiere multiplicar las instancias funcionales que limitan el poder de las mayorías electorales, aumentando la participación social en el proceso político (Rosanvallon, 2009, p. 192). Lo relevante no es tanto la división de poderes, sino la separación de estos en la medida en que cada uno se transforme en una instancia de control de los demás, ${ }^{8}$ lo que

7 El intelectual francés Marie-Jean-Antoine Nicolas de Caritat, marqués de Condorcet (1743-1794), además de ser un destacado pensador político, era matemático. Combinando ambas disciplinas escribió en 1785 su Ensayo sobre la aplicación del análisis a la probabilidad de las decisiones sometidas a la pluralidad de voces. En esta obra, describe la intransitividad como posible de la mayoría: entre un mismo electorado, y en el curso de una misma elección, es posible que una mayoría prefiera $\mathrm{A}$ antes que $\mathrm{B}$, que otra mayoría prefiera $\mathrm{B}$ antes que $\mathrm{C}$ y que una tercera mayoría prefiera $\mathrm{C}$ antes que $\mathrm{A}$. Las decisiones adoptadas por una mayoría popular siguiendo este modelo de escrutinio serían, pues, incoherentes con respecto a las que adoptaría un individuo racional. A este fenómeno se lo denominó la paradoja Condorcet. Estos estudios parecen señalar la desconfianza que le generaba a este pensador el fundar exclusivamente la democracia en las decisiones de un parlamento o asamblea.

8 Ya Hamilton señalaba, en el $\mathrm{N}^{\circ} 78$ de El Federalista, que los jueces no tienen ni la espada ni la bolsa, y que en ese sentido se trataba del más débil de los poderes del Estado. Sus decisiones incluso han de apoyarse en definitiva "en la ayuda del brazo ejecutivo hasta para que tengan eficacia sus fallos". En este contexto, los jueces están llamados a cumplir primordialmente una función de control, en particular cuando los poderes políticos (que deben encarnar fundamentalmente a la eficacia de la acción de gobierno) se exceden de sus marcos de actuación establecidos en la Constitución, sea en desmedro de los derechos de las personas, sea en las facultades de otro órgano o poder estatal. Inclusive hay autores que sostienen, avanzando aún más en esta dirección, que la Corte Suprema debe cumplir el 
tiende a garantizar que el comando del proceso político esté en manos de la generalidad social.

Una segunda dimensión que hay que atender para lograr la formación de una generalidad de multiplicación es la pluralización de los tiempos de lo político. En efecto, la cuestión de la temporalidad es muy relevante y tiende a desbaratar la idea de que las autoridades electoralmente elegidas implican una reedición permanente de la soberanía popular, como una suerte de reflujo del poder constituyente. Esa visión solo es aceptable si se la acota a momentos excepcionales. Si, en cambio, se la pretende convertir en una regla ordinaria, "la voluntad general no sería más que el capricho de cada momento”, como sostenía Renán (Rosanvallon, 2009, p. 195). De manera que es necesario superar la temporalidad presente para admitir que en la democracia (y, en verdad, en todo régimen político y social) conviven una pluralidad de temporalidades: el tiempo limitado del mandato electoral, el tiempo corto de la opinión, el tiempo largo de la constitución y el tiempo vigilante de la memoria. Todos ellos deberán confrontarse y ajustarse incesantemente, de modo de darle forma al ideal democrático. Así, de este movimiento permanente de reflexión -en sus diversas temporalidades- se arribará a la construcción histórica de la voluntad general. La democracia es, pues, una de las resultantes de esa construcción histórica del pueblo que no se limita a señalar los modos en los que una colectividad se gobierna a sí misma, sino que tiende a la conformación del régimen que posibilita la generación de una identidad común, en la que juegan la realización de valores, la búsqueda de objetivos generales y de largo plazo relativos a la forma que deba tener una sociedad deseada, imbricada con los propósitos, con los sentidos que ella albergue.

Finalmente, Rosanvallon (2009) considera otras dos cuestiones relevantes. Por la primera de ellas se advierte que la necesidad de reflexividad de la democracia no es solamente el resultado de la concurrencia de ciertas condiciones prácticas de una generalidad de multiplicación, sino que la reflexividad resulta una imposición lógica de la vida democrática. Ello es así porque, en contra de lo sostenido por los defensores de la democracia inmediata, es lógicamente impo-

rol de moderador del proceso político. Ello es así porque la funcionalidad del régimen político está ligada al equilibrio de sus poderes, de modo de buscar entre ellos la cooperación y no el bloqueo, amén de evitar la expansión de uno en perjuicio del otro. Con ese objetivo es conveniente que exista un órgano cuya misión sea velar por el correcto funcionamiento de la separación de poderes, aunque permaneciendo al margen de ellos. Este pouvoir neutre -como lo denomina Constant- en las repúblicas modernas coincide frecuentemente con el órgano al que se le ha encomendado el control de constitucionalidad. 
sible autofundar una democracia ex nihilo. Como agudamente señala el profesor del Collège de France, la revolución (y el poder constituyente que engendra) "quiere ser invención y ruptura, pero no se enuncia ni se comprende si no es en la denuncia de un mundo existente y en la referencia a los elementos de una historia" (Rosanvallon, 2009, p. 198). Es decir, no es posible un comienzo absoluto, sino que es necesaria la referencia a lo anterior, de manera de poder tomar una imprescindible distancia que permita advertir al sujeto reflexivo una diferencia, tornando posible de este modo la formación de una identidad o la formulación de un proyecto colectivo. Como afirma Ricoeur, "nunca se asiste al comienzo de la regla, sólo se puede ir de institución en institución" (Rosanvallon, 2009, p. 199, como se citó en Ost, 1999). La imposibilidad de la democracia para autoengendrarse va de la mano de su incapacidad para autocontrolarse. Rosanvallon se refiere, específicamente, a la validación de los mandatos o de los poderes efectuados por las asambleas, los cuales han fracasado en todas las latitudes y que en Francia desaparecieron cuando la Constitución de 1958 le otorgó al Consejo Constitucional la facultad de ser el árbitro final de las elecciones. Empero, creemos que la incapacidad de la democracia, entendida como mera democracia electoral, para controlarse a sí misma es bastante más amplia. En efecto, todo orden político requiere sostener un delicado equilibrio entre un poder eficaz y adecuadas instancias de control que tiendan a evitar y, en su caso, corregir posibles abusos o desviaciones que puedan presentarse. Los controles entre autoridades elegidas electoralmente han sido, y en esto coincidimos con Rosanvallon, de escasísima efectividad. Como muestra, basta mencionar que en 160 años de vivir bajo una Constitución ningún presidente o vicepresidente argentino ha sido destituido por acusación y juzgamiento del Congreso (juicio político), lo cual no habla tanto de la probidad de los gobernantes nacionales, sino más bien de la ausencia de controles políticos eficaces. Es en estos contextos, contar con terceros reflexivos -como los jueces constitucionales- adquiere un altísimo valor social y político, al punto de participar en la ampliación y profundización del sistema representativo, siempre, claro es, en el marco de una democracia compleja que recepte la categoría de la legitimidad de reflexividad.

Por otra parte, no debe perderse de vista que los tribunales constitucionales tienen confiada la misión de proteger los derechos individuales y colectivos, ${ }^{9}$

9 Adopto esta clasificación de los derechos en virtud de que son titularizados por sujetos de derecho individuales (la vida, la libertad, la propiedad) o por sujetos de derecho colectivos (los gremios, los usuarios y consumidores, etc.). El lector argentino está, en general, más familiarizado con la taxonomía de los derechos que propone diferenciar entre los derechos individuales de inspiración liberal, 
de manera de transformarlos en un auténtico coto vedado para las autoridades.

Marcel Gauchet (1995) ha señalado el importante desarrollo de la conciencia de los ciudadanos en torno al rol central que juegan los jueces en la defensa de sus derechos. Así, el Estado garantizador pasó a primer plano sobre el Estado gestor y planificador, apareciendo -paralelamente al desarrollo de este proceso- dos figuras que han pasado a ocupar un primer rango: la prensa y los jueces. Ese dúo de poder informal tiene por misión completar el sistema representativo y ello se aprecia, en el caso de los jueces, por la defensa de la individualidad, de la personalidad ante los abusos de los poderes públicos. Así, la acción judicial (particularmente la de los jueces que actúan en el ámbito del derecho público) se transforma en una pieza central del sistema representativo (en el sentido simbólico del término), pues es el factor clave que nos permite gobernarnos a nosotros mismos a través de otros hombres que nos gobiernan. De esta manera, los jueces son los guardianes del principio de composición del cuerpo social. Tienen por función mantenerlo inalterado, esto es, preservar las condiciones que hacen a su poder soberano, igual a sí mismo en todos los instantes del tiempo. Si el juez se le opone al pueblo, es con el fin de evitarle ponerse en contradicción consigo mismo (Gauchet, 1995).

A continuación, pasaremos a examinar las instituciones de la legitimidad de reflexividad de mayor relevancia: los tribunales constitucionales.

\section{Los tribunales constitucionales como instituciones de la legitimidad de reflexividad 3.1. El control de constitucionalidad como mutación de la democracia electoral}

Si el siglo XIX fue el siglo del Poder Legislativo (encarnado en parlamentos y congresos), el XX y los albores del XXI han sido los de la justicia constitucional. En efecto, así como las jefaturas de Gobierno y de Estado y las asambleas parlamentarias formaban parte del elenco estable de las constituciones clásicas, a partir de 1945 las constituciones de casi todo el mundo fueron incorporando la jurisdicción constitucional, ${ }^{10}$ que básicamente implica que un órgano imparcial

reconocidos en la Constitución de 1853/1960 (artículos 14, 17, 18, 19), los derechos sociales introducidos en la reforma de 1957 (artículo 14 bis o nuevo) y los derechos colectivos o de incidencia colectiva, incorporados en la reforma de 1994 (artículos 41 y 42, por ejemplo).

10 Es cierto que hay varias y notables excepciones. El sistema de control judicial de las leyes comienza a funcionar en los Estados Unidos en 1803, a partir de la sentencia de la Suprema Corte federal en el célebre caso Marbury v. Madison. Sin embargo, debe tenerse presente que la Constitución federal de 1787 no le otorgaba tal prerrogativa en forma expresa a la Suprema Corte de Justicia, que se "autorreconoció" pretorianamente dicha prerrogativa. 
e independiente, cuyos miembros no son elegidos popularmente, pueda dejar sin efecto (sea inter partes, sea erga omnes) o rectificar -conforme a las distintas modalidades y efectos vigentes, según cuál sea el sistema imperante en cada ordenamiento jurídico- una decisión proveniente de cualquier autoridad pública, incluso de leyes sancionadas por los parlamentos. A esto se lo denomina control de constitucionalidad.

El éxito de la jurisdicción constitucional no deja de ser sorprendente en cuanto propone una forma de legitimidad diferente a la derivada de la tradición democrática clásica, que entroniza como principio legitimador a la soberanía popular y que se vuelve operativa mediante el sufragio. Así, a) el pueblo elige a sus representantes mediante el voto; b) por medio de este procedimiento electoral se determina la voluntad mayoritaria del pueblo; c) mediante la votación de las leyes los elegidos expresan y traducen esta voluntad mayoritaria; d) por el control judicial de constitucionalidad los magistrados enjuician las leyes que expresan y traducen la voluntad mayoritaria del pueblo. Los tres primeros elementos ( $\mathrm{a}, \mathrm{b}, \mathrm{c})$ desarrollan la definición clásica de democracia. El cuarto elemento $(\mathrm{d})$ es extraño, ajeno a aquella definición. Se presenta como una ruptura, como una discontinuidad que configura más bien una encrucijada que nos permite acceder a una conformación política más compleja -también más contradictoria- que persigue hacer cohabitar bajo el mismo régimen los principios de la soberanía popular y los de la vigencia de los derechos humanos. Estos últimos, en la medida en que son reconocidos por los textos constitucionales, se convierten en un freno, en un límite a la voluntad expresada por los elegidos, aun cuando representen a una mayoría abrumadora.

La proliferación y el creciente activismo de los tribunales constitucionales han venido gestando una formidable mutación de las concepciones vigentes sobre la democracia, que obliga a plantearse revisiones y renovaciones urgentes de la filosofía política y jurídica. No obstante ser para algunos una "piedra de escándalo", en cuanto elemento disruptivo en el sentido ya señalado más arriba, el control de constitucionalidad llevado a cabo por las cortes o tribunales constitucionales es celebrado con un fuerte apoyo público (lo cual puede apreciarse globalmente, más allá de los sistemas considerados en su particularidad) y los tribunales que lo llevan a cabo son percibidos como exponentes de la más legítima institucionalidad democrática (Rosanvallon, 2009, p. 202).

En definitiva, los tribunales constitucionales se han convertido en la más destacada institución de la reflexividad, proponiendo una superación de las concepciones inmediatas y procesalistas de la democracia para permitir aden- 
trarnos en una versión más compleja y complicada de esta, que no se agote en la voluntad mayoritaria expresada electoralmente y el proceso decisional derivado de ello, sino que instale decididamente la efectiva vigencia de los derechos humanos como un principio legitimador de la misma envergadura que la soberanía popular. De este modo, nos adentramos en el concepto de democracia compleja de Rosanvallon y de lo que el constitucionalista francés Dominique Rousseau denomina democracia continua.

En esta inteligencia, y luego de describir sucintamente los dos grandes modelos de control de constitucionalidad: el liberal, con su énfasis en poner un límite al poder estatal, y el europeo-continental (kelseniano), enfocado en crear un legislador negativo que garantice la intangibilidad del sistema jerarquizado de fuentes, Rosanvallon se aboca a desarrollar lo que denomina la concepción democrático-reflexiva del control de constitucionalidad. Así, sostiene que, a las finalidades del control, además de comprender las ya mencionadas, debe añadírseles la de incrementar indirectamente el poder del ciudadano sobre las instituciones $\mathrm{o}$, al decir de Dominique Rousseau, poner en funcionamiento "un régimen alternativo y complementario de enunciación de la voluntad general" (como se citó en Rosanvallon, 2009, p. 204). Rosanvallon (2009) rastrea la búsqueda del fortalecimiento del poder ciudadano en la tradición norteamericana, en algunos elementos de la democracia jeffersoniana, preocupada por "la tiranía de las legislaturas" (p. 204, citando una carta de Jefferson a Madison). ${ }^{11}$ Sostiene que "en esta perspectiva, la judicial review podía ser asimilada a un poder popular de resistencia" y que Jefferson "apelaba a la adopción de una declaración de derechos, entendiéndola como un medio para 'garantizar el pueblo contra el gobierno federal”' (Rosanvallon, 2009, p. 204). En esta inteligencia, el mejor método para evitar que un Gobierno se convierta en opresivo consistiría en fortalecer el poder de los ciudadanos, de manera que la regla de derecho pueda ser en el marco de lo recién expuesto como equivalente a un mecanismo de democracia directa. En este orden de ideas, vuelven a aparecer las consideraciones de Gauchet (1995) cuando justifica que el juez puede limitar la fuerza de las mayorías, de manera que el pueblo no se contradiga a sí mismo.

11 También encuentra antecedentes en la Francia de la primavera de 1793. En efecto, en ese momento aparecieron concepciones semejantes a la jeffersoniana, en las que se postulaba que un jury nacional podría funcionar como "un medio para preservar al pueblo de la opresión del cuerpo legislativo" (Rosanvallon, 2009, p. 205). 


\subsection{Control de constitucionalidad y reflexividad}

De lo expuesto hasta aquí se concluye que los tribunales constitucionales son terceros, respecto a las autoridades elegidas por vía de sufragio, que ejercen una función de representación social y política, fruto de una mutación de la democracia basada en la transformación del vínculo entre derecho (control de constitucionalidad) y principio mayoritario (democracia electoral). Esta funcionalidad de los tribunales constitucionales viene a ratificar la idea de Rosanvallon sobre la existencia de una democracia compleja compuesta por varias dimensiones del pueblo. Particularmente confirma la existencia del pueblo-principio. ${ }^{12}$ Esta noción se encuentra fundada en la igualdad, en cuanto elemento que incluye a todos en la sociedad. Darle vida al pueblo-principio es asegurar el reconocimiento para todos de los bienes públicos que conforman el aspecto más estructural del bien común: los derechos humanos. Estos derechos constituyen la ciudadanía individual en tanto lazo de pertenencia a la comunidad, y reconocen la humanidad del sujeto en cuanto titular de una singularidad irreductible. Esta concepción del pueblo se encarna en el sujeto de derecho, que ya no refiere a un hombre meramente formal o ficcional, sino al "hombre más concreto que existe" (Rosanvallon, 2009, p. 194). En este orden de ideas, los tribunales constitucionales ejercen la función central de encarnar al pueblo-principio recordándoles a las autoridades popularmente elegidas que el soberano no se reduce a su expresión electoral mayoritaria, reeditando así, constantemente, la oposición del pueblo de los votos y el pueblo de los principios.

Otra cuestión que debe destacarse son las diferentes temporalidades en jue-

12 Las otras dos dimensiones son el pueblo-electoral y el pueblo-sociedad. El primero se expresa de manera inmediata a través de la conformación de una mayoría y de una minoría al cabo de una elección. A pesar de que los resultados de una elección dividen, correspondería considerar esta variante electoral del pueblo como constitutiva de la generalidad social, en tanto implica el reconocimiento de una igualdad radical manifestada en que todos pueden concurrir a las urnas a elegir a los candidatos de su preferencia. Es decir que, como dice Rosanvallon (2009, p. 193), el procedimiento que fundamenta al pueblo electoral tiende a unificar. Por otro lado, la cifra electoral posee una contundencia que permite cerrar toda controversia. El pueblo-social, por su parte, está conformado por la sucesión ininterrumpida de todas las minorías, es la sumatoria de las protestas, de las denuncias de situaciones vividas como la alteración de un orden justo, "manifestación sensible de lo que hace o deshace la posibilidad de un mundo en común. Es un pueblo cuya unidad está dada por ser una fuerza vital que se expresa en esa contradicción en movimiento que llamamos sociedad (Rosanvallon, 2009, p. 193). La faramalla de las cuestiones que constituyen el lazo colectivo nos permite entenderla como una generalidad social, que se expresa en el ámbito de lo que Rosanvallon denomina la "contrademocracia”, continente que es resultado de un conjunto de prácticas de control, de obstrucción y de enjuiciamiento, a través de las cuales la sociedad ejerce su poder de corrección y de presión. En consecuencia, junto al pueblo-electoral emergen las figuras de un pueblo-vigilante, de un pueblo-veto y de un pueblo-juez (Rosanvallon, 2007). 
go en los distintos pueblos. El pueblo-electoral está dominado por la inmediatez, por el corto plazo, mientras que el pueblo-principio inscribe generalmente su actuación en el largo plazo. No se trata de ser un mero árbitro en la faz agonal de la política (aunque, en ocasiones, deberá serlo), sino de participar en "la determinación y el fortalecimiento del ser-juntos” (Rosanvallon, 2009, p. 206). Por otra parte, al operar permanentemente a través de los derechos y principios fundamentales (constitucionales), los tribunales que ejercen control de constitucionalidad cumplen una función política de control y vigilancia de la memoria colectiva, haciendo presente los principios organizativos de la vida social y trayendo a la actualidad las promesa que la colectividad se hizo alguna vez a sí misma. Rosanvallon (2009), con todo, no coloca las distintas temporalidades en conflicto, sino que pretende integrar y armonizar los tiempos cortos del poder ejecutivo y del parlamento y los ciclos largos que impone el derecho constitucional y sus operadores más eminentes a través de una tarea permanente de reflexión que contribuya a la deliberación democrática y, más específicamente, a la formación de una voluntad común que permita superar el culto del presente y de la decisión inmediata (Rosanvallon, 2009, p. 211).

La armonización de las dos temporalidades y de los dos pueblos que se manifiestan a través de ellas les permite a los tribunales constitucionales dotar de mayor profundidad a la vida democrática, cumpliendo el rol de un tercero reflexivo productor de sentido. De este modo, los tribunales constitucionales participan en la ampliación y profundización del sistema representativo, facilitando la multiplicación de los distintos modos de representación.

Concluyendo este apartado, digamos, pues, que los tribunales constitucionales permiten corregir las desviaciones del sistema representativo (trayendo a los actuales representantes del pueblo-electorado los enunciados anteriores de la voluntad general, especialmente los consagrados en ese pacto e instrumento de gobierno a largo plazo que es la constitución) al tempo que desarrollan su funcionalidad democrática, enriqueciendo la deliberación política, permitiéndonos acceder a una profundización del sentido del con-vivir y del ser-juntos. De este modo, el control de constitucionalidad permite la alternancia de dos maneras de comprender y construir la voluntad general en las democracias: por una parte, la lógica del número, de las mayorías, que hace prevalecer la opinión inmediatamente predominante; por la otra, la lógica de la razón, que implica alargar la mirada gracias a la reflexividad, en la que la voluntad popular se construye a partir del razonamiento y del ejercicio de la memoria en torno a los compromisos que el pueblo asumió consigo mismo. La combinación dinámica 
de estos dos pueblos es tan indispensable como diferentes y complementarios son ellos entre sí, propendiendo a la reducción de la brecha entre las preferencias de hoy y las finalidades y significaciones de siempre, tornando así menos visible la demarcación entre la democracia como procedimiento y la democracia como contenido.

\subsection{La dificultad contramayoritaria}

Aquí retornamos a la pregunta con la que hemos comenzado este trabajo y que, de alguna manera, lo atraviesa íntegramente: ¿es democrático que un grupo de jueces no elegidos popularmente puedan imponer sus decisiones a los representantes del pueblo, esto es, contra el parlamento o congreso, o contra el Poder Ejecutivo?

Este es un debate que se originó hace más de doscientos años en los Estados Unidos y que, desde la década de 1960, se lo ha venido conociendo como la dificultad contramayoritaria de los jueces (refiriéndose a los que ejercen control de constitucionalidad), tal la denominación que introdujo Alexander M. Bickel (1986) en su ya clásico The Least Dangerous Branch de 1962. En los últimos cincuenta años, la cuestión ha merecido ser estudiada por varios de los constitucionalistas y politólogos más eminentes de los Estados Unidos y, más recientemente, se ha convertido en una cuestión clave de la teoría política y jurídica en Europa y en América Latina, toda vez que, como ya hemos tenido oportunidad de referir, la jurisdicción constitucional es hoy un fenómeno global.

En general, los objetores de la jurisdicción constitucional consideran -como bien reseña Rosanvallon (2009)- que

la defensa de la razón constitucional en el fondo no hace más que reactualizar las viejas prevenciones liberales contra el poder del número y que las antiguas figuras aristocráticas y de exigencia de capacidades previas [capacitaires] han adoptado hoy la máscara de los jueces constitucionales. (p. 226)

Al decir de Carlos Nino (1997), el control de constitucionalidad judicial implica el ejercicio de un cierto elitismo epistémico que se lleva mal con la democracia. El propio Bickel (1986) sostiene que los jueces constitucionales invocan al pueblo para justificar la revisión judicial cuando, en realidad, lo que hacen es justificar una frustración de "la voluntad de aquellos que efectivamente representa[ban] la mayoría prevaleciente" (p. 16). La revisión judicial representa "el poder aplicar y dar forma a la Constitución, en cuestiones de 
la mayor importancia, contra los deseos de las mayorías legislativas que son, a su vez, incapaces de torcer la decisión judicial” (Bickel, 1986, p. 17). Si la democracia implica que los ciudadanos puedan conducirse según sus propios juicios (y, por añadidura, de los representantes que libremente eligen), ese derecho resulta gravemente afectado por las intervenciones de la Corte Suprema (Waldron, 1993), en tanto máxima expresión de la jurisdicción constitucional en el sistema jurídico-político norteamericano, de manera que dicho tribunal es percibido por los objetores y sus seguidores como una institución contramayoritaria y, en consecuencia, antidemocrática.

Rosanvallon (2009, p. 227) se pregunta si, en atención a la dificultad contramayoritaria, resultaría necesario dotar a los tribunales constitucionales de una legitimidad directamente electoral. Luego de pasar revista a los disímiles antecedentes de la jurisdicción constitucional en los Estados Unidos y en Francia, el profesor del Collège de France distingue entre dos tipos de elecciones de jueces: la "pura elección o elección de confianza", como procedimiento de consagración popular de una autoridad, que tiene como finalidad explícita la confianza de los electores en una persona y, a fin de cuentas, en una institución; y una "elección partidaria", que necesariamente conlleva una confrontación de intereses o ideas, en la que de lo que se trata es de elegir entre personas que compiten o, en su caso, de escoger entre puntos de vista antagónicos. Con buen criterio, Rosanvallon (2009) sostiene que la elección partidaria de los jueces atenta contra la misión y la funcionalidad de los tribunales constitucionales, en tanto suprime de hecho la dimensión de generalidad que le es consustancial. En efecto, "una corte constitucional debe encarnar estructuralmente una capacidad de reflexividad e imparcialidad que quedaría destruida por la inscripción en un orden partidario" (Rosanvallon, 2009, p. 237). ${ }^{13}$ Por su parte, la pura elección o la elección de confianza implica un mecanismo en el que generalmente hay un solo candidato (no hay competencia), que es nominado con anterioridad (existen varios procedimientos al respecto) generalmente sobre la base de sus aptitudes y competencias. En un segundo paso se realiza la elección que, en rigor, es una confirmación..$^{14}$ Es cierto que estos mecanismos

\section{Cursivas en el original.}

14 En la mayoría de los estados que integran los Estados Unidos se utiliza un sistema similar al descrito, denominado Merit Plan. En el ámbito federal, el mecanismo es totalmente distinto: los jueces son elegidos por el presidente con el acuerdo del Senado, que, cuando se trata de ministros de la Suprema Corte, requiere una mayoría calificada. En la Argentina existe un sistema prácticamente idéntico al imperante para la designación de jueces federales en los Estados Unidos (los jueces federales inferiores son designados por el presidente con acuerdo del Senado con base en una terna elevada 
tienen una fuerte carga utópica y que su funcionamiento en la realidad tiende a ser colonizado por cuestiones políticas más bien coyunturales. Ello conduce a la conclusión poco auspiciosa, desde la lógica del sufragio como factor que otorga legitimidad, de que la distinción fáctica entre los dos tipos de elecciones es muchas veces harto difícil. De allí que Rosanvallon (2009) concluya que en materia de tribunales constitucionales no se debe intentar legitimarlos por el recurso al voto, sino que más bien "resulta decisivo argumentar la importancia que reviste la no elección para esas funciones" (p. 237).

Es por este orden de razones que parece preferible no intentar legitimar los tribunales constitucionales -en tanto instituciones de la reflexividad- mediante la vía de la "democratización por sufragio", es decir, aceptando como paradigma democrático verdadero o superior la lógica de la elección, sino que la justificación debe provenir de la propia lógica de la reflexividad, esto es, de la instauración de instituciones que puedan garantizar el interés general más allá de las diferencias del plano electoral. La conocida distinción entre la faz agonal y la faz arquitectónica de la política se ajusta sin dificultad a la democracia contemporánea. Es dable referirse así a una faz agonal de la democracia caracterizada por la competencia entre personas y programas diferenciados, y a una democracia arquitectónica, que permite elevar la mirada por sobre las coyunturas y conflictividades cotidianas que se encuentran al cuidado de las instituciones reflexivas o imparciales. La democracia actual es, así, necesariamente dual. La clave no es confundir una con la otra, sino, por el contrario, profundizar las condiciones de legitimidad propias de cada una de estas esferas del universo democrático (Rosanvallon, 2009, p. 239).

Finalmente, es oportuno hacer mención a una de las críticas que suelen

por el Consejo de la Magistratura al cabo de un concurso público). En el año 2003 se dictaron dos decretos del Poder Ejecutivo, los 222 y 588, que limitaron la discrecionalidad del presidente en la designación de los jueces de la Corte Suprema, en el primer caso, y de los jueces federales inferiores, en el segundo. El mecanismo se iniciaba con la postulación de un candidato a cubrir la vacante. El Ministerio de Justicia podía recibir apoyos o rechazos a la postulación, que podía provenir tanto de personas físicas como jurídicas. Se celebraba una audiencia pública a efectos de que el postulante pudiese dar razón de su candidatura y, especialmente, de los rechazos o críticas que se le habían formulado. Luego, el Ministerio de Justicia elaboraba un informe en el que daba cuenta del procedimiento. Lo que surgiese de dicho informe no era vinculante para el Poder Ejecutivo. La iniciativa, inaugurada con la postulación de Eugenio Zaffaroni como magistrado de la Corte Suprema, fue recibida con buenas expectativas, las cuales fueron defraudadas ante los recortes de información que se advertían en el informe del Ministerio. El sistema se desacreditó y prácticamente nunca se utilizó en las designaciones de los jueces federales de cámara y de $1^{\text {a }}$ instancia, so pretexto de mediar razones de urgencia para concretar los nombramientos. El procedimiento reseñado no constituía un mecanismo de elección, pero sí de nominación que, de haber sido bien implementado, podría equivaler a una elección de confianza. 
formulársele recurrentemente a la justicia constitucional: el riesgo de tornar posible "el Gobierno de los jueces", desplazando a las autoridades elegidas por el voto popular. En primer lugar, señalemos que tal hipótesis no se ha verificado jamás en toda la historia del constitucionalismo, sino que, más bien, la amenaza más palpable es la opuesta: que las presiones de los poderes estatales que se conforman electoralmente neutralicen la tarea de reflexividad de los tribunales constitucionales. Por otro lado, la posibilidad de actuación de los tribunales se encuentra limitada: normalmente, la interpretación de los tribunales tiene que ajustarse a un texto; hay una actitud prudencial característica de los jueces constitucionales que es la autorrestricción (self-restraint), por la que se expresa una cierta deferencia por el obrar de los poderes electivos, todo lo cual conduce a sancionar un acto o una norma con su inconstitucionalidad cuando se verifica una incompatibilidad inconciliable entre esta y la Constitución; luego, hay cuestiones que generalmente son irrevisables en tanto actos de naturaleza política (v.gr. declaración de guerra, estado de sitio, etc.); en algunos sistemas el control de la norma es anterior a su sanción (previo), mientras que en otros es posterior; en algunos el efecto es derogatorio, mientras que en otros es solamente para el caso concreto; etc.); los criterios de designación son estrictamente de competencia o idoneidad técnica; en tanto instituciones reflexivas, su proceder está fuertemente orientado por criterios éticos avalados en un fuerte prestigio social, todo lo cual genera confianza (al estilo de las "instituciones invisibles" de Arrow) o autoridad. ${ }^{15}$

\section{A modo de conclusión}

"The question is", said Alice, "whether you can make words mean so many different things".

"The question is", said Humpty Dumpty, "wich is to be the master-that's all".

(Lewis Carroll, Througt the Looking-Glass and what Alice found there)

15 Es interesante traer a colación la distinción que realizaban los romanos entre autorictas y potestas. Mientras que la primera es el saber socialmente reconocido, la segunda es el poder socialmente reconocido. Desde esta perspectiva podría pensarse que el juez constitucional, a través de su razonamiento, no está en sentido último haciendo ejercicio de un "poder", sino de un "saber" que se le ha reconocido. A lo sumo, puede pensarse que si el juez tiene poder -que efectivamente lo tiene-, este se legitima por su "saber". Es decir que la potestad y la autoridad, en los sentidos apuntados, responden a ámbitos distintos y a fuentes de legitimidad también diferentes. El gobernante no gobierna en virtud de su conocimiento o sabiduría, sino porque se le reconoce un poder que se legitima por la elección popular o en el consenso. En cambio, el juez constitucional no es elegido popularmente, sino que es designado por su saber. 
We are under a Constitution, but the Constitution is what the judges say it is.

(Charles Evans Hughes -1862-1948-, Chief Justice de la Suprema Corte de los Estados Unidos entre 1930 y 1941)

Luego de haber recorrido los aspectos más sustanciales del tratamiento que Pierre Rosanvallon hace de la legitimidad de reflexividad en general y de su aplicación en particular a la función que desempeñan en la democracia los tribunales constitucionales, finalizaremos esta exploración con algunas reflexiones personales que pretenderemos vertebrar con las del eminente pensador francés.

Está claro que Rosanvallon lleva adelante una explicación que gira permanentemente en torno al reconocimiento, diferenciación y complementariedad entre visiones dualistas de la democracia: la democracia electoral y la democracia reflexiva; la democracia del número y la democracia de la razón; la democracia de la lucha por el poder y la democracia que vela por la realización de un proyecto común, del ser-juntos. En suma, la democracia como régimen político y la democracia como forma de sociedad. Se acepta, al menos en el desarrollo que hemos recorrido, que electoralmente los elegidos por el voto representan a los votantes, es decir, a los gobernados. Esta es una legitimidad que se presenta como naturalizada y que se enuncia como verdadera. Claramente, el esfuerzo argumentativo de Rosanvallon está orientado a dar cuenta de la existencia de una legitimidad complementaria a la electoral (la de reflexividad).

Sin embargo, debemos preguntarnos: ¿es realmente equiparable la voluntad de los ciudadanos con la voluntad de sus representantes elegidos por sufragio? Si existiese una identificación perfecta entre ambas voluntades, el Legislador sería, entonces, la encarnación del soberano, de modo que trastocar la ley mediante el control de constitucionalidad que ejercen los tribunales constitucionales implicaría un atentado contra la soberanía popular, de manera que solamente podrían salvar la legitimidad de esos tribunales explicaciones como las que procura Rosanvallon (2009). Empero, también es posible sostener que existen diferencias entre la voluntad de los representantes y las de los representados. De hecho, los fenómenos que dan cuenta de la crisis de representatividad tienden a verificar la existencia de esa distancia (y que el propio Rosanvallon (2007) plasma tan brillante y persuasivamente con su concepto de contrademocracia). Ya Juan Jacobo Rousseau (2001a; 2001b) sostenía, en su crítica a la representación, que los gobernantes pasaban a constituir un cuerpo intermedio que desarrollaba un "yo particular" enfrentado al "yo común" del pueblo, manifestando su esfuerzo constante por adueñarse de la soberanía. En este sentido, precisamente lo que el constitucionalismo viene a decir es que vivir bajo una constitución 
encierra la pretensión de que los representantes políticos se sometan a reglas y a principios de decisión definidos por otros, distintos de ellos mismos, concretamente por el pueblo soberano, que es el autor de la constitución. Esta, pues, es la expresión del pueblo, mientras que la ley es la expresión de los representantes. La segunda está subordinada a la primera, de manera que para que una ley sea democráticamente válida debe someterse al designio del pueblo contenido en la constitución.

Se presentan, entonces, dos esferas bien diferenciadas: la de los ciudadanos, conformada por los derechos y los principios organizativos de los poderes estatales, y la de los representantes, que deben procurar respetar y llevar adelante lo que les mandan sus representados. Para que esta distinción tenga sentido es fundamental que las dos esferas cuenten con su expresión institucional. Si alguno de los dos se quedase sin voz, sin poder pronunciar el derecho, quedaría sojuzgado a merced del otro y nos hallaríamos frente a una democracia parcial, falsificada. En esta inteligencia, los tribunales constitucionales son los órganos de la esfera ciudadana o, más específicamente, se encuentran en la intersección de las dos esferas, vigilando (desde la imparcialidad y la reflexividad, al decir de Rosanvallon) la vigencia de los derechos de las personas involucrados en medio de las decisiones de los órganos políticos de representación electoral. El control de constitucionalidad es una función imprescindible para garantizar la supremacía de la constitución en tanto garantía del ser-juntos, y encuentra su legitimidad democrática en su misión de asegurar la tutela de los derechos y libertades. El respeto de estos derechos es una precondición de un régimen democrático y, además, los órganos que llevan a cabo esta garantía (los tribunales constitucionales) resultan en sí mismos una instancia necesaria de las democracias contemporáneas.

Conforme nos lo ha demostrado Rosanvallon, el origen de los poderes no es el único criterio distintivo de la democracia, por los menos en una concepción de la democracia que quiera ser más compleja y satisfactoria. Por supuesto que las mayorías tienen derecho a tomar decisiones mediante los órganos representativos elegidos por el voto, pero, como hemos visto a lo largo de todo este trabajo, hay otros criterios de legitimidad -además del electoral- que permiten controlar el modo en el que ese poder mayoritario se ejerce (lo que suele denominarse "legitimidad de ejercicio"). Si esto no fuera así, estaríamos hablando de una democracia sometida a un único control: el que el elector puede llevar a cabo de una elección a otra (v.gr. censurando a sus elegidos, el "voto castigo"). Es por ello que la justicia constitucional aparece como esa instancia de control permanente que impide que las mayorías puedan llevarse por delante todo 
(incluso las decisiones superiores preexistentes, constitucionales). En la medida en que los gobernados puedan ejercer este control continuo y eficaz sobre los gobernantes a través de los jueces constitucionales, estos se legitimarán democráticamente..$^{16}$

En consecuencia, y como primera conclusión, debemos consignar que las dos cuestiones principales que tienden a legitimar a los tribunales constitucionales como instituciones reflexivas son, por un lado, sus funciones de garantes de los derechos y libertades y, por otro lado, transformarse en la instancia de control de los poderes electorales en nombre y en favor de los gobernados. El individuo emancipado, que debe ser el sujeto de la democracia, logra a través de la justicia constitucional el medio para que le sea reconocido ese estatus que se traduce operativamente en su condición de sujeto de derecho, titular de libertades y controlador de aquellos a los que elige como representantes.

Es evidente que la democracia moderna ha sufrido muchos e importantes cambios desde fines del siglo XVIII hasta la actualidad: la expansión del sufragio, la democracia de partidos, las tecnocracias de antes y de ahora, la encarnación de la desconfianza en la contrademocracia, etc. Está también claro que el advenimiento y desarrollo de la justicia constitucional presupone un concepto de democracia que ya no puede ser definido simplemente como el gobierno del pueblo por el propio pueblo (electoral), sino como gobierno de una voluntad general formada, en parte, bajo la influencia que el pueblo ejerce a través de los representados, y en parte por las decisiones de los jueces constitucionales. Esta nueva mutación de la democracia reconoce el poder de la mayoría, pero también designa una suerte de reino de los principios y valores democráticos en el que residen las libertades y derechos de cada uno. Ese reino no es otro que el reino de la constitución, del cual los tribunales constitucionales son operadores imprescindibles. En otros términos, para que la democracia sea considerada legítima, ya no basta con que se hallen representadas las mayorías del momento presente, no basta con la inmediatez; la democracia para ser legítima debe ser una democracia constitucional con todas las implicancias que venimos considerando.

¿Cómo conciliar regla de la mayoría con constitución y, por tanto, con tutela de los derechos y control sobre el poder, garantizados por esa instancia de reflexividad

16 Sin embargo, el control no se limita al que se pueden ejercer entre sí las instituciones del Estado. Como bien enseña Rosanvallon (2007), hay un control que es el que se ejerce desde la democracia de los poderes indirectos diseminados en el cuerpo social, la democracia de la desconfianza organizada frente a la democracia de la legitimidad electoral: la contrademocracia. 
que son los tribunales constitucionales? La principal condición de posibilidad creemos que es el empoderamiento del ciudadano y de la sociedad. En esa línea, la justicia constitucional tiene varias e importantes funciones que desempeñar: el control de los poderes elegidos electoralmente; la tutela de los derechos humanos, especialmente de aquellos que tienden a realizar la democracia en todas sus dimensiones y acepciones, tales como la libertad de expresión, los derechos de reunión, asociación, manifestación y a la información; el acceso a la justicia; promover a través de sus decisiones el desarrollo de canales participativos y deliberativos; entre otras.

La democracia, en suma, ya no es unidimensional ni puede reducirse a simple aritmética. En cambio, se ha vuelto más y más compleja y tiende a transformarse en un sistema jurídicamente sujeto a reglas de creciente exigencia en el que se destaca la justicia constitucional como exponente de la legitimidad de reflexividad, ${ }^{17}$ la que, evitando los eventuales atropellos de las mayorías circunstanciales sobre las minorías y los individuos y asegurando el respeto de los derechos, permite el despliegue de la autonomía de cada ciudadano, asentada en su humana dignidad, fundamento de toda forma civilizada del con-vivir.

\section{Bibliografía}

Álvarez Álvarez, F.D. (2003). Legitimidad democrática y control judicial de constitucionalidad. Díkaion, Revista de Fundamentación Jurídica, (17)12, 147-177.

Annunziata, R. (2012). Hacia un nuevo modelo de lazo representativo. La representación de proximidad en las campañas electorales de 2009 y 2011 en Argentina. En Cheresky, I. y Annunziata, R. (Comps.), Sin programa, sin promesas. Liderazgo y procesos electorales en Argentina (pp. 45-87). Prometeo.

Bickel, A. (1986). The Least Dangerous Branch (2a ed.). Yale University Press.

Gauchet, M. (1995). La Révolution des pouvoirs. La souveraineté, le peuple et la répresentation. 1789. 1799. Gallimard.

Hughes, C. E. (1971). La Suprema Corte de los Estados Unidos (2a ed.). Fondo de Cultura Económica. Madison, H. J. (1966). The Federalist Papers. Doubleday.

Nino, C. S. (1997). La Constitución de la Democracia Deliberativa. Gedisa.

Rosanvallon, P. (2007). La contrademocracia. La política en la era de la desconfianza. Manantial.

17 La legitimidad de reflexividad formulada por Rosanvallon (2009), como he intentado demostrarlo en el presente estudio, es un componente imprescindible de una concepción robusta de la democracia. Con anterioridad, he examinado otros nueve argumentos que procuran conciliar democracia con magistratura constitucional (Álvarez Álvarez, 2003). 
Rosanvallon, P. (2009). La legitimidad democrática. Imparcialidad, reflexividad, proximidad. Manantial. Rousseau, J. J. (2001a). Discurso sobre el origen y los fundamentos de la desigualdad entre los hombres. El Ateneo.

Rousseau, J. J. (2001b). El contrato social. El Ateneo.

Vita, L. (2009). La crítica de Nietzsche al Estado moderno. Lecciones y Ensayos, 86, 213-233.

Waldron, J. (1993). A Right-Based Critique of Constitutional Rights. Oxford Journal of Legal Studies, 13(1), 18-51. 